\title{
Perioperative cerebral and somatic oxygenation in neonates with hypoplastic left heart syndrome or transposition of the great arteries
}

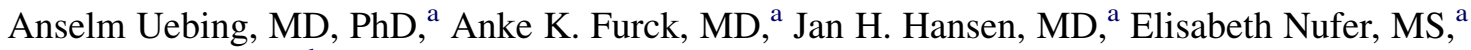 \\ Jens Scheewe, MD, ${ }^{\mathrm{b}}$ Peter Dütschke, MD, ${ }^{\mathrm{c}}$ Olaf Jung, MD, ${ }^{\mathrm{a}}$ and Hans-Heiner Kramer, MD, PhD ${ }^{\mathrm{a}}$
}

\begin{abstract}
Objective: Significant depression in cerebral oxygen saturation has been observed in patients with hypoplastic left heart syndrome (HLHS) undergoing Norwood operations. We monitored cerebral oxygen saturation with near-infrared spectroscopy before and after this procedure. Patients with transposition of great arteries (TGA) before and after arterial switch operation were also studied to elucidate whether post-cardiopulmonary bypass $(\mathrm{CPB})$ changes in cerebral oxygen saturation are related to $\mathrm{CPB}$ or hemodynamic alterations inherent in singleventricle physiology.
\end{abstract}

Methods: We monitored 33 patients with HLHS and 20 with TGA 24 hours before and 48 hours after CPB. In addition to cerebral oxygen saturation, routine measurements of oxygen transport and delivery were performed.

Results: Preoperatively, cerebral oxygen saturation was higher in patients with HLHS than with TGA $(61 \% \pm$ $7 \%$ vs $56 \% \pm 8 \%, P=.04)$. After $\mathrm{CPB}$, cerebral oxygen saturation was markedly depressed in both groups but increased toward end of monitoring (HLHS vs TGA minimal value $42 \% \pm 12 \%$ vs $54 \% \pm 11 \%, P<.001$, value 48 hours after CPB $62 \% \pm 7 \%$ vs $80 \% \pm 8 \%, P<.0001$ ). Routine measures of oxygen delivery, such as arterial and central venous oxygen saturations, were similar at minimal cerebral oxygen saturation and 48 hours after CPB.

Conclusions: Depression of cerebral oxygen saturation is prevalent among neonates with congenital heart disease regardless of whether univentricular or biventricular circulation is present, suggesting that cerebral desaturation is mainly induced by CPB's effect on cerebral blood flow. Routine measures of oxygen delivery fail to indicate cerebral desaturation. (J Thorac Cardiovasc Surg 2011;142:523-30)

Complex cyanotic congenital heart defects such as hypoplastic left heart syndrome (HLHS) and transposition of the great arteries (TGA) necessitate neonatal surgical intervention. The Norwood procedure and its modifications are used as initial palliation for HLHS, and the arterial switch operation (ASO) is used to correct TGA. Both interventions these days are being performed with decreasing morbidity and mortality. ${ }^{1,2}$ Despite this improvement, postoperative hemodynamic instability and potential adverse effects of hypothermic cardiopulmonary bypass $(\mathrm{CPB})$ on oxygen delivery are suggested to be associated with adverse outcome and long-term neurologic dysfunction. ${ }^{3}$

Near-infrared spectroscopy (NIRS) provides a noninvasive means of evaluating regional cerebral oxygen satura-

\footnotetext{
From the Departments of Congenital Heart Disease and Pediatric Cardiology, ${ }^{a}$ Thoracic and Cardiovascular Surgery, ${ }^{\mathrm{b}}$ and Anesthesiology and Intensive Care Medicine, ${ }^{\mathrm{c}}$ University Hospital of Schleswig-Holstein, Campus Kiel, Kiel, Germany. Supported by the Fördergemeinschaft Deutsche Kinderherzzentren e.V.

Disclosures: Authors have nothing to disclose with regard to commercial support. A.U. and A.K.F. contributed equally to the article.

Received for publication June 8, 2010; revisions received Dec 17, 2010; accepted for publication Jan 20, 2011; available ahead of print March 30, 2011.

Address for reprints: Hans-Heiner Kramer, MD, PhD, Department of Congenital Heart Disease and Pediatric Cardiology, University Hospital of SchleswigHolstein, Campus Kiel, Arnold-Heller-Strasse 3, Haus 9, 24105 Kiel, Germany (E-mail: kramer@pedcard.uni-kiel.de). $0022-5223 / \$ 36.00$

Copyright (C) 2011 Published by Elsevier Inc. on behalf of The American Association for Thoracic Surgery

doi:10.1016/j.jtcvs.2011.01.036
}

tion $\left(\mathrm{ScO}_{2}\right)$ and somatic oxygen saturation $\left(\mathrm{SsO}_{2}\right){ }^{4}$ Previous studies have demonstrated that $\mathrm{ScO}_{2}$, although maintained as much as possible during CPB with deep hypothermia and selective antegrade cerebral perfusion, is significantly depressed relative to $\mathrm{SsO}_{2}$ in the early post-CPB period after the Norwood procedure in patients with HLHS, suggesting that cerebrovascular resistance is increased after deep hypothermic CPB. ${ }^{5}$ Hemodynamic instability after the Norwood operation, with excessive pulmonary blood flow through a modified Blalock-Taussig shunt (MBTS) and significant diastolic runoff from the cerebral vascular bed, has also been discussed as possibly contributing to this phenomenon. ${ }^{3}$

We decided to monitor continuously regional oxygen saturation in patients with HLHS before and after the Norwood operation and also in neonates with TGA before and after the ASO to elucidate further whether postoperative changes in regional tissue oxygenation are related to inherent effects of deep hypothermic $\mathrm{CPB}$ or to hemodynamic alterations related to the single-ventricle physiology.

\section{MATERIALS AND METHODS Patients}

Thirty-three consecutive patients with HLHS undergoing the modified Norwood operation and another 20 consecutive patients with TGA undergoing the ASO were enrolled in the study. All patients underwent surgery in the period from September 2006 to December 2008. All parents gave their 


$$
\begin{aligned}
& \text { Abbreviations and Acronyms } \\
& \begin{array}{ll}
\Omega & =\text { oxygen excess factor } \\
\mathrm{ASO} & =\text { arterial switch operation } \\
\mathrm{avDO}_{2} & =\text { arteriovenous oxygen content } \\
& \text { difference }
\end{array} \\
& \mathrm{CPB}=\text { cardiopulmonary bypass } \\
& \mathrm{HLHS}=\text { hypoplastic left heart syndrome } \\
& \mathrm{MBTS}=\text { modified Blalock-Taussig shunt } \\
& \mathrm{NIRS}=\text { near-infrared spectroscopy } \\
& \mathrm{PCICU}=\text { pediatric cardiac intensive care unit } \\
& \mathrm{SaO}_{2}=\text { arterial oxygen saturation } \\
& \mathrm{ScO}_{2}=\text { cerebral oxygen saturation } \\
& \mathrm{SsO}_{2}=\text { somatic oxygen saturation } \\
& \mathrm{SvO}_{2}=\text { central venous oxygen saturation } \\
& \mathrm{TGA}=\text { transposition of the great arteries }
\end{aligned}
$$

informed consent to the collection and anonymous analysis of the data, and the study protocol was approved by the local research ethics committee.

\section{Preoperative Management}

Preoperatively, all patients with HLHS were treated according to a standardized protocol, as previously described, ${ }^{1}$ consisting of afterload reduction with sodium nitroprusside or phentolamine mesylate (INN phentolamine mesilate), low-dose prostaglandin $\mathrm{E}_{1}$, furosemide, enteral feeding, and avoidance of mechanical ventilation or inotropic support.

Of the 20 patients with TGA, 9 (45\%) required a balloon atrioseptostomy on the day of birth, and 2 patients transiently required mechanical ventilation. No additional preoperative medical treatment was necessary in this patient group.

\section{Surgical Techniques}

Patients with HLHS underwent the Norwood procedure with MBTS placement ( 3.0 or $3.5 \mathrm{~mm}$ ). All patients with HLHS were operated on with low-flow antegrade selective cerebral perfusion during reconstruction of the aortic arch so that deep hypothermic circulatory arrest could be avoided. Only a single patient with an absent truncus brachiocephalicus received a 4-mm right ventricle-pulmonary artery conduit and needed a 7-minute period of deep hypothermic circulatory arrest.

The technique used for the ASO has previously been reported. ${ }^{6}$ The Lecompte maneuver was used in all cases. Associated procedures included closure of a ventricular septal defect in 2 cases.

In both the HLHS and the TGA groups, the $\mathrm{pH}$-stat method was used for cooling to a temperature of $18^{\circ} \mathrm{C}$ and was continued during CPB. The patients were rewarmed with the $\alpha$-stat method. In all cases, hemofiltration was routinely used before weaning from CPB. In all patients, general anesthesia was maintained with inhaled sevoflurane, intravenous sufentanil, and rocuronium bromide.

\section{Postoperative Management}

Postoperatively, patients with HLHS were continued on afterload reduction therapy with either sodium nitroprusside or phentolamine mesylate, and inotropic support was achieved with epinephrine and enoximone. ${ }^{1}$ For patients with TGA, a similar postoperative drug regimen was applied. The type of afterload reduction was determined clinically, with analysis of the effect of different types of afterload reduction on the postoperative course initially not intended. For patients with HLHS who had cyanosis, we aimed for a postoperative hemoglobin level of about 14 to $16 \mathrm{~g} / \mathrm{dL}$, corresponding with a hematocrit greater than $40 \%$. For patients with TGA, we aimed for a hemoglobin level in the range of 12 to $14 \mathrm{~g} / \mathrm{dL}$, corresponding with a hematocrit of at least $30 \%$.

\section{Perioperative Monitoring and Data Acquisition}

In all patients, both those with HLHS and those with TGA, invasive arterial blood pressure monitoring was initiated after admission to the pediatric cardiac intensive care unit (PCICU). Arterial oxygen saturation $\left(\mathrm{SaO}_{2}\right)$ was also continuously monitored. Immediately before surgery, a central venous line was placed in the superior vena cava, and each patient was intubated and mechanically ventilated.

Postoperative monitoring in the PCICU consisted of the continuous measurement of invasive arterial blood pressure, central venous blood pressure, $\mathrm{SaO}_{2}$, and end-tidal $\mathrm{PCO}_{2}$. Arterial blood gas values were checked hourly for the first 24 hours and thereafter at 2- to 4-hour intervals, depending on the patient status. Central venous blood gas values were analyzed at 4-hour intervals for the first 48 postoperative hours, starting after hemodynamic stabilization after arrival in the PCICU and afterward at clinically appropriate intervals. Blood gas tensions were reported at $37^{\circ} \mathrm{C}$ (Radiometer ABL, Copenhagen, Denmark). For hemodynamic monitoring, the IntelliVue system (Philips Healthcare, Best, The Netherlands) was used. All hemodynamic and blood gas data were recorded in the patients PCICU charts. Continuous measurements were recorded hourly. All hemodynamic and respiratory data were manually transferred in hourly intervals into a custom-made data base.

For the continuous recording of regional oxygen saturation, NIRS probes were placed on the patient's midline forehead $\left(\mathrm{ScO}_{2}\right)$ and slightly to the right of midline on the $\mathrm{T} 10$ to $\mathrm{L} 2$ posterior flank $\left(\mathrm{SsO}_{2}\right)$. The probes were monitored by a dual detector device (Somanetics INVOS 5100C; Somanetics Corporation, Troy, Mich). Cerebral and somatic NIRS data were stored digitally with a sampling rate of 1 per second and transferred into a commercial spreadsheet application. Thereafter, all values recorded in an hour were averaged and imported into the custom-made database system so that they could be matched with the hemodynamic and respiratory data of the respective time points.

Hemodynamic, respiratory, and NIRS data were collected and analyzed for the 24-hour interval before CPB and the 48-hour period after CPB.

\section{Analysis and Calculations}

Demographic and operative patient data were collected at the time of analysis from the patient records (Table 1). The durations of CPB, aortic crossclamping, and deep hypothermic circulatory arrest were also recorded, as were the duration of ventilation, circulatory drug support, and duration of PCICU treatment.

To quantify differences between $\mathrm{ScO}_{2}$ and $\mathrm{SsO}_{2}$ between patients with HLHS and those with TGA, the following parameters were calculated (Figure 1): (1) average $\mathrm{ScO}_{2}$ and $\mathrm{SsO}_{2}$ calculated for the first 10 preoperative hours, (2) minimal postoperative $\mathrm{ScO}_{2}$, (3) interval from the end of $\mathrm{CPB}$ to the minimal $\mathrm{ScO}_{2}$, (4) $\mathrm{ScO}_{2}$ and $\mathrm{SsO}_{2}$ at the end of registration (48 hours after $\mathrm{CPB}$ ), and (5) interval needed to increase $\mathrm{ScO}_{2}$ to halfway toward the late postoperative level.

To delineate any potential differences in blood pressure and routine postoperative measurements of oxygen delivery at the times of minimal and maximal postoperative $\mathrm{ScO}_{2}$, central venous and arterial blood pressures, $\mathrm{SaO}_{2}$, central venous oxygen saturation sampled from the central venous catheter placed in the superior vena cava $\left(\mathrm{SvO}_{2}\right)$, arteriovenous oxygen content difference $\left(\mathrm{avDo}_{2}\right)$, oxygen excess factor $(\Omega)$, and hemoglobin concentration were all compared at both time points in both groups. The $\Omega$ value is regarded as a valid measure of systemic oxygen delivery and is calculated as the ratio of $\mathrm{SaO}_{2}$ to the difference between $\mathrm{SaO}_{2}$ and $\mathrm{SvO}_{2}{ }^{7}$

Low values for $\mathrm{SvO}_{2}$ have also been shown to indicate impaired systemic oxygen delivery. ${ }^{7}$ We therefore compared postoperative $\mathrm{SvO}_{2}$ values with regional tissue oxygenation measured by $\mathrm{NIRS}\left(\mathrm{ScO}_{2}\right.$ and $\left.\mathrm{SsO}_{2}\right)$. 
TABLE 1. Demographic and surgical patient data

\begin{tabular}{|c|c|c|c|}
\hline & $\begin{array}{c}\text { HLHS } \\
(\mathbf{n}=\mathbf{3 3})\end{array}$ & $\begin{array}{c}\text { TGA } \\
(\mathbf{n}=\mathbf{2 0})\end{array}$ & $\begin{array}{c}P \\
\text { value }\end{array}$ \\
\hline Male (No.) & $20(61 \%)$ & $16(80 \%)$ & NS \\
\hline Birth weight $(\mathrm{kg}$, mean $\pm \mathrm{SD})$ & $3.3 \pm 0.5$ & $3.5 \pm 0.6$ & NS \\
\hline Age at surgery $(\mathrm{d}$, mean $\pm \mathrm{SD})$ & $6.4 \pm 4.4$ & $7.1 \pm 3.1$ & NS \\
\hline Weight at surgery $(\mathrm{kg}$, mean $\pm \mathrm{SD})$ & $3.2 \pm 0.5$ & $3.5 \pm 0.6$ & NS \\
\hline BSA at surgery $\left(\mathrm{m}^{2}\right.$, mean $\left.\pm \mathrm{SD}\right)$ & $0.21 \pm 0.02$ & $0.22 \pm 0.02$ & NS \\
\hline Duration of CPB (min, mean \pm SD) & $144 \pm 22$ & $151 \pm 22$ & NS \\
\hline $\begin{array}{l}\text { Duration of aortic crossclamping } \\
\quad(\text { min, mean } \pm \text { SD })\end{array}$ & $44 \pm 14$ & $88 \pm 19$ & $<.0001$ \\
\hline $\begin{array}{l}\text { Duration of DHCA } \\
\quad(\min , \text { mean } \pm \mathrm{SD})\end{array}$ & $0(0-7)$ & $0(0-8)$ & NS \\
\hline Early (30-d) survival (No.) & $33(100 \%)$ & $20(100 \%)$ & NS \\
\hline $\begin{array}{l}\text { Postoperative ventilation } \\
\quad(\mathrm{h}, \text { mean } \pm \mathrm{SD})\end{array}$ & $58(36-192)$ & $50(15-133)$ & .07 \\
\hline $\begin{array}{l}\text { Postoperative PCICU stay } \\
\quad(\mathrm{h}, \text { mean } \pm \mathrm{SD})\end{array}$ & $88(50-696)$ & $72(43-133)$ & .08 \\
\hline $\begin{array}{l}\text { Duration of epinephrine use } \\
\quad(h, \text { mean } \pm \text { SD })\end{array}$ & $42(22-575)$ & $27(16-104)$ & .10 \\
\hline $\begin{array}{l}\text { Duration of sodium nitroprusside } \\
\text { use } \mathrm{h}, * \text { mean } \pm \mathrm{SD} \text { ) }\end{array}$ & $51(3-125)$ & $31(13-88)$ & NS \\
\hline $\begin{array}{l}\text { Duration of phentolamine mesylate } \\
\text { use }(\mathrm{h}, * \text { mean } \pm \mathrm{SD})\end{array}$ & $71(27-696)$ & $71(31-96)$ & NS \\
\hline $\begin{array}{l}\text { Duration of enoximone use } \\
\quad(h, \text { mean } \pm \mathrm{SD})\end{array}$ & $82(29-696)$ & $71(42-128)$ & .05 \\
\hline \multicolumn{4}{|c|}{$\begin{array}{l}H L H S \text {, Hypoplastic left heart syndrome; } T G A \text {, transposition of the great arteries; } N S \text {, } \\
\text { not significant; } B S A \text {, body surface area; } C P B \text {, cardiopulmonary bypass, } D H C A \text {, deep } \\
\text { hypothermic circulatory arrest; } P C I C U \text {, pediatric cardiac intensive care unit. *So- } \\
\text { dium nitroprusside was used in } 14 \text { patients with hypoplastic left heart syndrome } \\
\text { and in all patients with transposition of the great arteries; phentolamine mesylate } \\
\text { was used in } 19 \text { patients with hypoplastic left heart syndrome and in } 5 \text { patients with } \\
\text { transposition of the great arteries. }\end{array}$} \\
\hline
\end{tabular}

Low $\mathrm{ScO}_{2}$ after $\mathrm{CPB}$ has been suggested to be related to low $\mathrm{PaCO}_{2} .{ }^{5}$ The relationship between $\mathrm{ScO}_{2}$ and $\mathrm{PaCO}_{2}$ was therefore calculated at the time of minimal $\mathrm{ScO}_{2}$ for both groups, patients with HLHS and those with TGA.

To detect any impact of low $\mathrm{ScO}_{2}$ after CPB on adverse outcome, we divided the HLHS and TGA groups according to the median duration of PCICU treatment. The end of PCICU treatment was defined as the point at which mechanical ventilation and circulatory drug support were ultimately terminated. Thereafter we compared post-CPB $\mathrm{ScO}_{2}$ values in patients with durations of PCICU treatment longer and shorter than the median with a general linear model repeated-measures analysis of variance.

Regional tissue oxygenation was also compared between patients with HLHS who received sodium nitroprusside to reduce systemic afterload after the Norwood operation and those who received phentolamine mesylate.

\section{Statistics}

Data are presented as mean $\pm \mathrm{SD}$ or median and range as appropriate. Comparisons between groups and variables were made with the Student $t$ test or Mann-Whitney $U$ test, and paired analyses were performed with the Student $t$ test or Wilcoxon signed rank test as appropriate. Univariate linear regression analyses were performed to assess associations between variables.

A general linear model repeated-measures analysis of variance was used to compare NIRS values between the subgroups of patients with durations of PCICU treatment longer and shorter than the median and between those who received sodium nitroprusside to reduce systemic afterload and those who received phentolamine mesylate.
All analyses were preformed with SPSS 17.0 for Windows software (SPSS Inc, an IBM Company, Chicago, Ill). For multiple comparisons of blood gas data and NIRS data in subsequent postoperative intervals, the level of significance was adjusted according to the number of comparisons made with the Bonferroni method.

\section{RESULTS}

\section{Patient Characteristics and Surgical Data}

Demographic and surgical patient data are summarized in Table 1. Patients with HLHS and patients with TGA did not differ with regard to sex distribution, birth weight, age, weight, and body surface area at surgery. CPB times and deep hypothermic circulatory arrest times were also similar in the 2 groups. Patients with TGA had a significantly longer aortic crossclamp time. There were nonsignificant trends toward longer ventilation time and longer PCICU treatment in patients with HLHS $(P=.07$ and $P=.08$, respectively). Durations of epinephrine and enoximone support also tended to be longer in the HLHS group $(P=.10$ and $P=.05$, respectively).

None of the patients with HLHS and patients with TGA died within 30 days after the operation. All patients with HLHS survived until the subsequent hemi-Fontan operation.

\section{Preoperative and Postoperative Profiles of Regional Tissue Oxygenation}

Figure 1 shows the data for regional oxygen saturation as recorded for 24 hours before and 48 hours after CPB in both patients with HLHS and patients with TGA. In the 10 hour period before $\mathrm{CPB}$, mean $\mathrm{ScO}_{2}$ was significantly higher in patients with HLHS than in patients with TGA $(61 \% \pm$ $7 \%$ vs. $56 \% \pm 8 \%, P=.04)$. $\mathrm{SsO}_{2}$ did not differ between patients with HLHS and patients with TGA when comparing the mean values of the first 10 hours of preoperative monitoring ( $60 \% \pm 8 \%$ vs. $61 \% \pm 8 \%, P$ not significant).

After cessation of $\mathrm{CPB}$, there was a marked decrease in $\mathrm{ScO}_{2}$ in both groups of patients with congenital heart disease. The minimal $\mathrm{ScO}_{2}$ was recorded after $5.1 \pm 1.6$ hours in patients with HLHS and after $4.7 \pm 2$ hours in patients with TGA ( $P$ not significant). In patients with HLHS, $\mathrm{ScO}_{2}$ fell after CPB to a minimum of $42 \% \pm 12 \%$, whereas in patients with TGA it fell to $54 \% \pm 11 \%(P<.001)$. Thereafter, $\mathrm{ScO}_{2}$ continuously increased and reached a plateau approximately 24 hours after weaning from $\mathrm{CPB}$, with $\mathrm{ScO}_{2}$ values in the range of the 48-hour level. After 48 hours, $\mathrm{ScO}_{2}$ was $62 \% \pm 7 \%$ in patients with HLHS and $80 \% \pm$ $8 \%$ in patients with TGA $(P<.0001)$. In patients with HLHS, it took $5.5 \pm 4.7$ hours to increase $\mathrm{ScO}_{2}$ halfway toward the 48-hour level. In patients with TGA, the necessary interval was in the same range $(4.1 \pm 3.3$ hours, $P$ not significant).

Compared with $\mathrm{ScO}_{2}, \mathrm{SsO}_{2}$ showed less marked changes during postoperative monitoring. In patients with TGA 
Hypoplastic Left Heart Syndrome
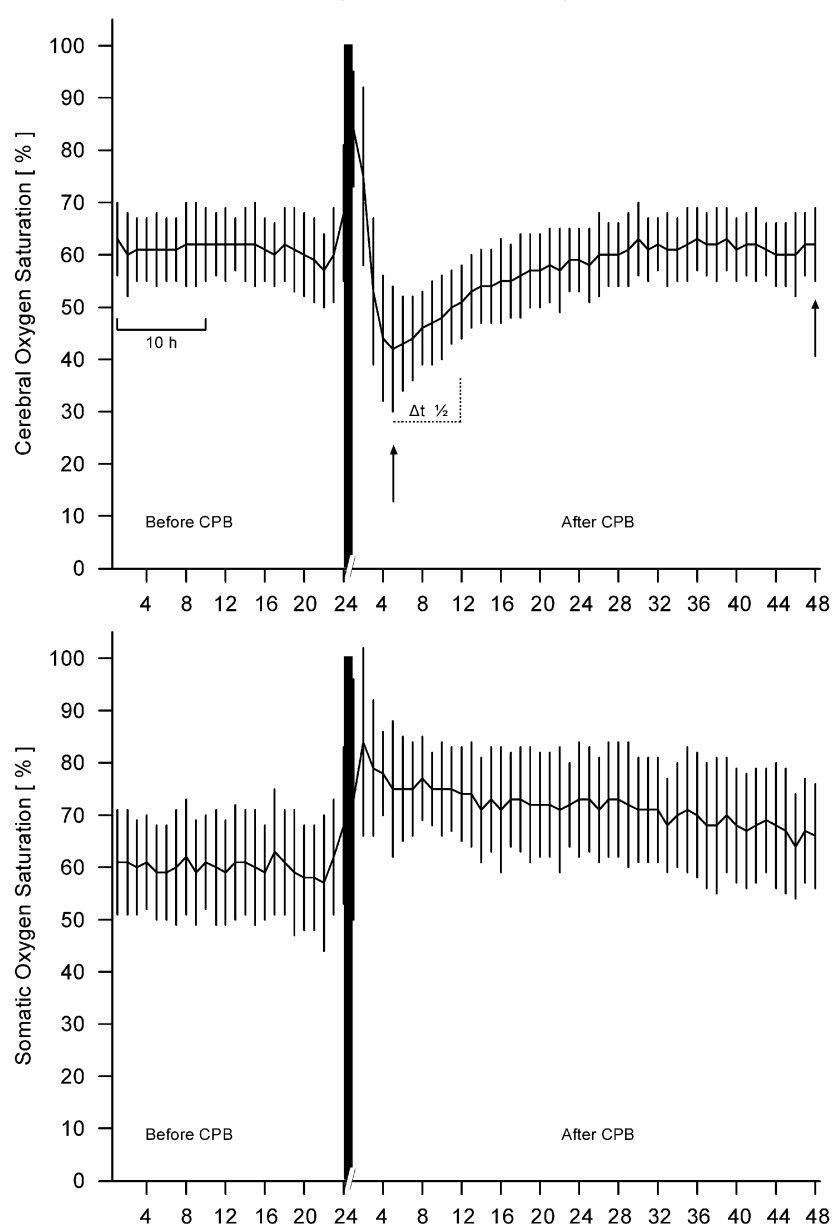
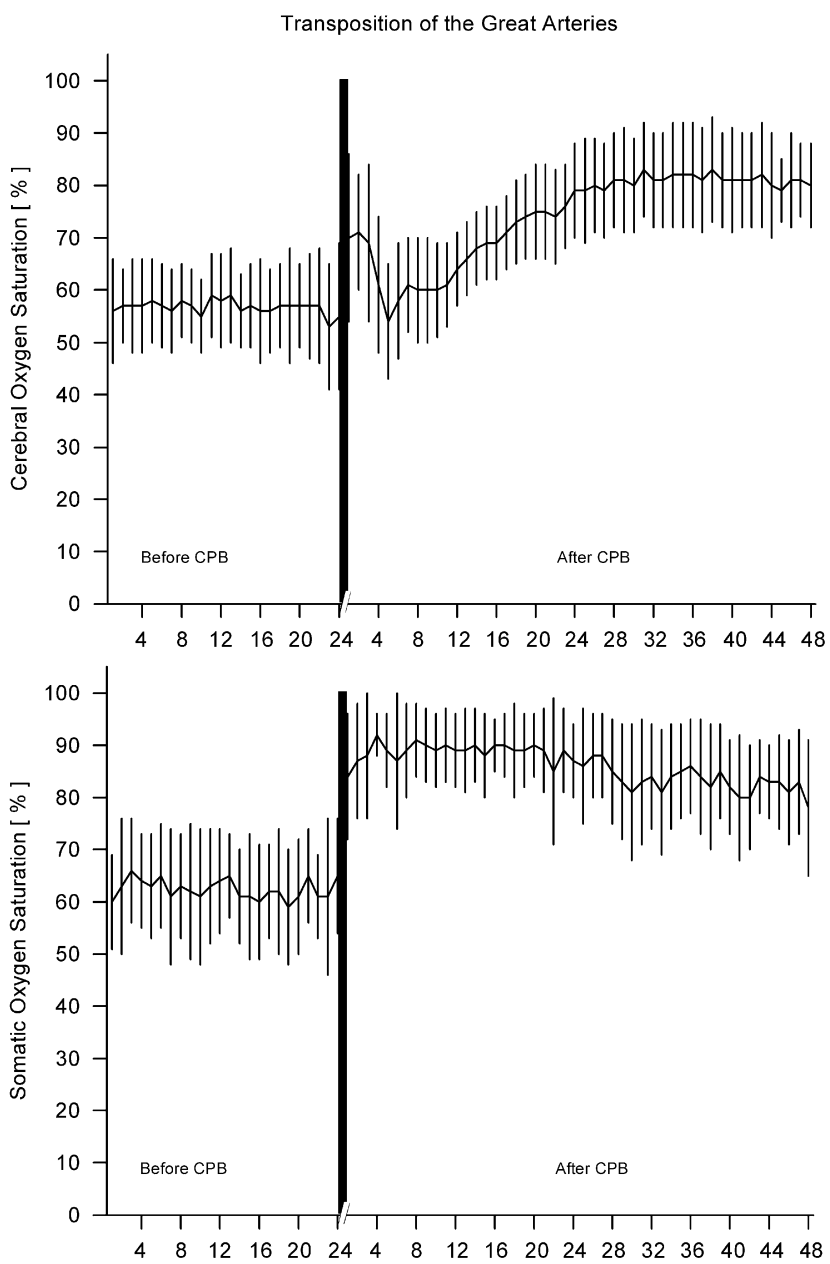

FIGURE 1. Perioperative profiles of regional tissue oxygenation. The black vertical bar indicates the cardiopulmonary bypass (CPB) period. In the left upper panel, the 10-hour period taken to compare near-infrared spectrographic data before cardiopulmonary bypass is marked. The time points of minimal cerebral oxygen saturation and late postoperative cerebral oxygen saturation are marked with an arrow. $\Delta 1 / 2$, Time to increase cerebral oxygen saturation halfway toward its 48-hour value.

without cyanosis, $\mathrm{SsO}_{2}$ was higher both early and late after CPB. The difference in postoperative $\mathrm{SsO}_{2}$ between patients with TGA and patients with HLHS is exemplified by the statistical difference between the postoperative peak and 48-hour values (TGA vs HLHS peak $\mathrm{SsO}_{2} 92 \% \pm 4 \%$ vs $84 \% \pm 15 \%, 48$-hour $\mathrm{SsO}_{2} 78 \% \pm 13 \%$ vs $66 \% \pm$ $10 \%, P<.05$ and $P<.0001$, respectively). In both groups, $\mathrm{SsO}_{2}$ decreased mildly from the early postoperative peak to the level of the 48-hour value.

\section{$\mathrm{ScO}_{2}$, Blood Pressure, and Conventional Hemodynamic Measurements}

The changes in postoperative $\mathrm{ScO}_{2}$ were most pronounced in the early postoperative period. To assess whether the depression in $\mathrm{ScO}_{2}$ early after CPB and the subsequent recovery were accompanied by changes in blood pressure and parameters related to oxygen transport and delivery, central venous pressure, mean arterial blood pressure, hemoglobin levels, $\mathrm{SaO}_{2}, \mathrm{SvO}_{2}, \mathrm{avDo}_{2}$, and $\Omega$ were measured at the times of minimal and maximal postoperative $\mathrm{ScO}_{2}$, and these values were compared. These data are given in Table 2. In patients with HLHS, mean arterial blood pressure was higher at the time of minimal $\mathrm{ScO}_{2}$. Other than this, none of the parameters changed significantly from the time of minimal $\mathrm{ScO}_{2}$ to that of maximal $\mathrm{ScO}_{2}$. In patients with TGA, only $\mathrm{avDo}_{2}$ and $\Omega$ indicated an improvement oxygen delivery; however, $\mathrm{SaO}_{2}$ and $\mathrm{SvO}_{2}$ also failed to indicate impaired cerebral tissue oxygenation.

\section{Postoperative Regional Oxygenation Saturations, $\mathrm{SaO}_{2}$, and $\mathrm{Svo}_{2}$}

Figure 2 shows the data for postoperative regional oxygen saturations in conjunction with the simultaneous measurements of $\mathrm{SaO}_{2}$ and $\mathrm{SvO}_{2}$, as obtained from blood gas analysis, for both groups of patients with congenital heart disease. As mentioned previously, blood gas data 
TABLE 2. Blood pressures and measurements related to oxygen transport and delivery at minimal and maximal postoperative cerebral tissue oxygenations

\begin{tabular}{|c|c|c|c|c|c|c|}
\hline & \multicolumn{3}{|c|}{ HLHS } & \multicolumn{3}{|c|}{ TGA } \\
\hline & $\mathrm{Sco}_{2} \min$ & $\mathrm{Sco}_{2} \mathrm{max}$ & $P$ value & $\mathrm{ScO}_{2} \mathrm{~min}$ & $\mathrm{Sco}_{2} \mathrm{max}$ & $P$ value \\
\hline $\mathrm{CVP}(\mathrm{mm} \mathrm{Hg})$ & $7.8 \pm 2.3$ & $8.8 \pm 2.6$ & NS & $7.2 \pm 1.9$ & $8.7 \pm 2.1$ & NS \\
\hline Mean ABP $(\mathrm{mm} \mathrm{Hg})$ & $60.0 \pm 8.1$ & $53.6 \pm 7.9$ & .003 & $61.1 \pm 11.5$ & $57.3 \pm 10.0$ & NS \\
\hline Hemoglobin $(\mathrm{g} / \mathrm{dL})$ & $14.1 \pm 1.0$ & $14.2 \pm 1.0$ & NS & $13.6 \pm 1.9$ & $12.6 \pm 1.6$ & .07 \\
\hline $\mathrm{SaO}_{2}(\%)$ & $80.0 \pm 5.7$ & $81.0 \pm 4.8$ & NS & $99.0 \pm 1.3$ & $99.0 \pm 0.8$ & NS \\
\hline $\mathrm{SvO}_{2}(\%)$ & $62.2 \pm 9.0$ & $63.3 \pm 9.0$ & NS & $71.7 \pm 8.8$ & $76.9 \pm 6.3$ & .07 \\
\hline $\mathrm{avDo}_{2}(\mathrm{~mL} / \mathrm{dL})$ & $3.0 \pm 1.4$ & $3.5 \pm 1.3$ & NS & $6.1 \pm 2.8$ & $3.4 \pm 1.3$ & $<.001$ \\
\hline$\Omega$ & $5.3 \pm 1.9$ & $5.4 \pm 2.2$ & NS & $3.0 \pm 0.9$ & $5.0 \pm 2.0$ & $<.001$ \\
\hline
\end{tabular}

All values are mean \pm SD. HLHS, Hypoplastic left heart syndrome; TGA, transposition of the great arteries; $\mathrm{ScO}_{2}$ min, minimal cerebral tissue oxygenation; $S c \mathrm{O}_{2}$ max, maximal cerebral tissue oxygenation; $C V P$, central venous pressure; $N S$, not significant; $A B P$, arterial blood pressure, $\mathrm{SaO}_{2}$, arterial oxygen saturation; $\mathrm{SvO}_{2}$, venous oxygen saturation; $a v \mathrm{Do}_{2}$, arteriovenous oxygen content difference; $\Omega$, oxygen excess factor $\left(\mathrm{SaO}_{2} /\left[\mathrm{SaO}_{2}-\mathrm{SvO}_{2}\right]\right)$.

could not be collected hourly, so comparisons between blood gas data and data on regional tissue oxygenation had to be made after calculation of mean values for consecutive 4-hour intervals. These mean values were compared to delineate potential differences between blood gas and NIRS data. This analysis showed that in patients with HLHS, $\mathrm{SvO}_{2}$ was significantly higher than $\mathrm{Sco}_{2}$ at 4 to 8,8 to 12,12 to 16 , and 16 to 20 hours after surgery $(P<.005$ for each interval). In patients with TGA, comparable differences could be found. In the latter group, the difference between $\mathrm{SvO}_{2}$ and $\mathrm{ScO}_{2}$ was significant at 4 to 8,8 to 12 , and 12 to 16 hours after surgery $(P<.005$ for each interval). Compared with $\mathrm{SsO}_{2}, \mathrm{SvO}_{2}$ was lower during the early postoperative period both in patients with HLHS and in patients with TGA. In patients with HLHS, the difference in $\mathrm{SvO}_{2}$ and $\mathrm{SsO}_{2}$ was significant at 4 to 8,8 to 12,12 to 16 , and 16 to 20 hours $(P<.001$ for each interval). In patients with TGA, the difference remained significant until the interval from 32 to 36 hours after cessation of CPB $(P<.001$ for each interval). $\mathrm{SaO}_{2}$ remained unchanged during the entire period of postoperative monitoring and was unrelated to the changes in regional tissue oxygenation (Figure 2).

\section{$\mathrm{ScO}_{2}$ and Adverse Outcome}

Adverse outcome was defined as duration of PCICU treatment longer than the median of the respective group (Table 1). In both patients with HLHS and patients with TGA, there was no difference in postoperative $\mathrm{ScO}_{2}$ between the subgroups of patients with adverse outcome and those without when comparing the $\mathrm{ScO}_{2}$ curves for the respective subgroups with repeated-measures analysis of variance (Figure 3). There was also no relationship between $\mathrm{SsO}_{2}$ and adverse outcome in either group.

\section{Correlates With Low Postoperative $\mathrm{Sco}_{2}$}

We found a significant correlation between $\mathrm{ScO}_{2}$ and the corresponding $\mathrm{PCO}_{2}$ in patients with HLHS at time of minimal $\mathrm{ScO}_{2}(r=0.49, P<.01)$. We could not, however, demonstrate such a relationship for the groups of patients with TGA ( $r=-0.05, P$ not significant).
In the HLHS groups, 14 patients received sodium nitroprusside to reduce afterload and 19 patients received phentolamine mesylate, so the $\mathrm{ScO}_{2}$ curves for these 2 HLHS subgroups were compared with repeated-measures analysis of variance. The type of afterload reduction did not affect the postoperative course of $\mathrm{ScO}_{2}$ in patients with HLHS.

\section{DISCUSSION}

The major finding of this study was that $\mathrm{ScO}_{2}$ decreased significantly after CPB in neonates undergoing surgery for complex congenital heart disease. A dip in $\mathrm{ScO}_{2}$ was found both in patients with HLHS who had cyanosis after the Norwood operation and in patients with TGA who did not have cyanosis after the ASO. We therefore presume that the postoperative depression in $\mathrm{ScO}_{2}$ is most likely related to a direct effect of hypothermic CPB rather than to the presence or absence of a parallel circulation.

We studied patients with HLHS and TGA. Because the patient groups were similar with regard to age at operation, duration of $\mathrm{CPB}$, and the type of postoperative medical treatment, they seemed particularly suitable for a study aiming to delineate any differences in the course and level of regional tissue oxygenation potentially related to the presence or absence of cyanosis or the type of circulation.

The decrease in $\mathrm{ScO}_{2}$ immediately after $\mathrm{CPB}$ has previously been reported to be almost universally present in patients with HLHS after the Norwood operation..$^{3,5,8}$ It has been speculated by Hoffmann and coworkers ${ }^{5}$ that this depression is related to a transient increase in cerebrovascular resistance. Phelps and coworkers, ${ }^{3}$ however, showed that the postoperative decrease in $\mathrm{ScO}_{2}$ tended to be less pronounced in patients with HLHS who had right ventricular to pulmonary artery conduit (Sano shunt) placement relative to those who had MBTS placement. They therefore speculated that an abnormal cerebral blood flow caused by the proximity of the MBTS to the cerebral arteries also contributes to this phenomenon. Except in 1 case, all patients with HLHS studied by us were operated on with MBTS placement. We therefore can not contribute to the 

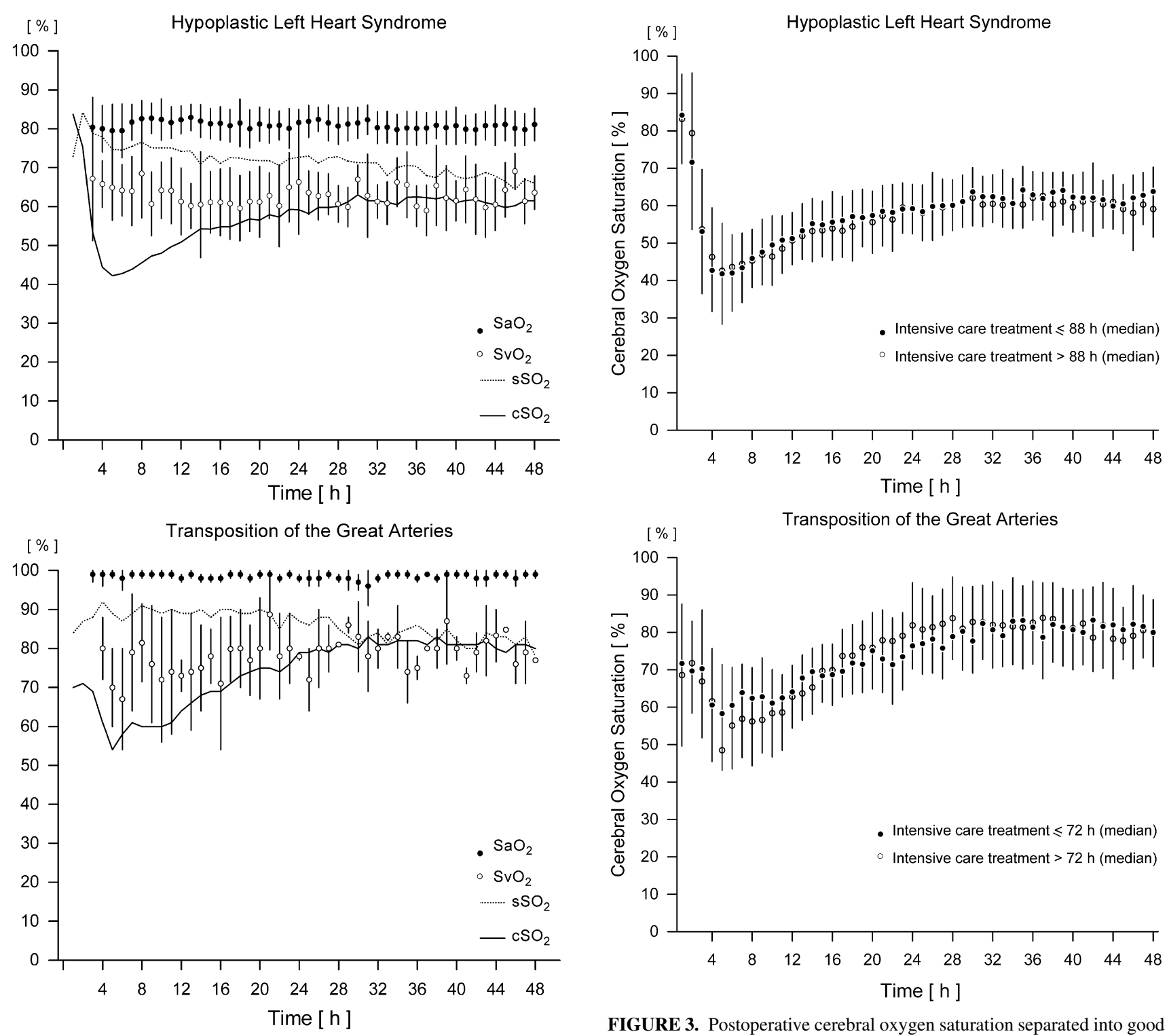

FIGURE 2. Postoperative regional tissue oxygenations, arterial oxygen saturation $\left(\mathrm{SaO}_{2}\right)$, and central venous oxygen saturation $\left(\mathrm{SvO}_{2}\right)$. $\mathrm{sSO}_{2}$, Somatic oxygen saturation, $\mathrm{CSO}_{2}$, cerebral oxygen saturation.

determination of whether MBTS placement particularly impairs $\mathrm{ScO}_{2}$ in patients with HLHS. The fact that patients with TGA showed a similar decrease in $\mathrm{ScO}_{2}$, albeit without cyanosis after surgery on a higher level, strongly suggests that cerebrovascular autoregulation is significantly disturbed after CPB and that this disturbance is the predominant contributor to abnormal early postoperative cerebral oxygen delivery.

In our cohort of patients with HLHS early after neonatal surgery, we could not find any significant relationship between routine measures of oxygen transport and delivery such as hemoglobin concentration, $\mathrm{SvO}_{2}, \mathrm{avDo}_{2}$, or $\Omega$ (Figure 2 and Table 2). $\mathrm{SvO}_{2}$ has been reported to be closely

FIGURE 3. Postoperative cerebral oxygen saturation separated into good outcomes and adverse outcomes (duration of intensive care treatment longer than the median of the respective group).

related to $\mathrm{ScO}_{2}$ in older children with a univentricular circulation. ${ }^{9}$ This discrepancy with our early postoperative data might be explained by the fact that postoperative $\mathrm{SvO}_{2}$ measurement could be in error when sampling central venous blood from a central venous line placed in the superior vena cava in close proximity to pulmonary venous blood flow through an open interatrial communication. This might cause $\mathrm{SvO}_{2}$ and thus $\mathrm{avDo}_{2}$ to be overestimated by sampling a mixture of central venous and pulmonary venous blood. We could not, however, even demonstrate a trend toward higher $\mathrm{SvO}_{2}$ or any difference in $\mathrm{avDo}_{2}$ or $\Omega$ from the early post-CPB period toward the end of NIRS monitoring. Furthermore, the increase in $\mathrm{SvO}_{2}$ from the time point of minimal $\mathrm{ScO}_{2}$ to the time of maximal $\mathrm{SvO}_{2}$ in patients with TGA was also not pronounced. 
$\mathrm{Li}$ and colleagues ${ }^{10}$ have also reported on a correlation between $\mathrm{ScO}_{2}$ and $\mathrm{SvO}_{2}$, collecting these data in 11 patients with HLHS during a period of 72 hours after the Norwood operation. In that prospective study, data were collected at 2-hour intervals and only if sedation, paralysis, and ventilatory or hemodynamic treatments were not changed for 15 minutes before the sampling. In our study, NIRS data were collected continuously, and central venous blood was sampled 4-hourly, starting after stabilization of the patient after arrival on the PCICU and thereafter at different time points. $\mathrm{SvO}_{2}$ data were therefore not available for all patients at all time points, but NIRS data were, and data may well have been collected at times of hemodynamic instability or change. Furthermore, even though a statistically significant relationship between $\mathrm{ScO}_{2}$ and $\mathrm{SvO}_{2}$ exists in postoperative patients with HLHS, the strength of this relationship does not seem strong enough to predict with accuracy a specific cerebral NIRS value from a given value of $\mathrm{SvO}_{2}$. For example, $\mathrm{SvO}_{2}$ of $60 \%$ did correspond with $\mathrm{ScO}_{2}$ in the range $30 \%$ to $70 \%$ in the study of $\mathrm{Li}$ and colleagues. ${ }^{10}$ We presume that the difference in data collection and the weakness of the relationship between $\mathrm{SvO}_{2}$ and $\mathrm{ScO}_{2}$ could explain why the marked and rapid changes in $\mathrm{ScO}_{2}$ observed in our patients early after the Norwood operation were not mirrored by similar changes in $\mathrm{Svo}_{2}$ or derived measures of oxygen transport and delivery. We suggest therefore that NIRS monitoring may be an important complementary tool in an attempt to monitor neonates comprehensively early after complex neonatal heart surgery.

We found significantly higher blood pressures at the time of lowest $\mathrm{ScO}_{2}$ early after the Norwood operation (Table 2). This finding is compatible with a recent study by Lucas and coworkers, ${ }^{11}$ which showed an inverse relationship between mean arterial blood pressure and $\mathrm{ScO}_{2}$ measured by NIRS in healthy human subjects when altering blood pressure pharmacologically. Our finding, and likewise that of Lucas and coworkers, ${ }^{11}$ may be explained by cerebral vasoconstriction or dilatation introduced by the pharmaceutical agents used. Postoperative changes in skin blood flow, however, could also explain these findings. ${ }^{12}$

NIRS measures the oxygen saturation of blood in the arterial, capillary, and venous vascular compartments. In the brain, the venous compartment has the highest capacitance. An elevated central venous pressure may therefore increase the volume of blood in the venous compartment more than those in the arterial and capillary compartments, potentially resulting in lower NIRS values. We could not detect any difference in central venous pressures, however, when comparing the time points of the lowest and highest postoperative NIRS $\mathrm{ScO}_{2}$ values (Table 2). Changes in central venous pressure are therefore unlikely to explain the depression in $\mathrm{ScO}_{2}$ early after neonatal surgery with $\mathrm{CPB}$ reported here.

Experimental data suggest that significant postoperative cerebral deoxygenation is likely to impact negatively on neurodevelopmental outcome in children undergoing neonatal surgery with $\mathrm{CPB} .{ }^{13,14}$ It therefore seems vital to detect any cerebral desaturation and to develop strategies to reduce the degree of desaturation. The decrease in $\mathrm{ScO}_{2}$ is to some extent mirrored by a peak in $\mathrm{SsO}_{2}$ and vice versa, with $\mathrm{ScO}_{2}$ increasing with time and $\mathrm{SsO}_{2}$ falling during the first 48 hours after CPB. The observation of this phenomenon has led to the development of the hypothesis that the depression in $\mathrm{ScO}_{2}$ could be aggravated by redistribution of blood from the cerebral circulation toward the splanchnic circulation, because $\alpha$-blocking vasodilative drugs such as phentolamine mesylate are more active in splanchnic, muscle, and skin vascular beds than in the brain, with its intense autoregulation. ${ }^{5}$ This redistribution could potentially be aggravated by aggressive postoperative vasodilator therapy. Although we could not demonstrate any difference in the level and course of postoperative $\mathrm{ScO}_{2}$ between our subgroups of patients with HLHS treated with sodium nitroprusside and with phentolamine mesylate, further prospective studies with vasodilative drugs that have been shown to increase cerebral blood flow after $\mathrm{CPB}$, such as milrinone, are warranted and underway. ${ }^{15}$

Phelps and coworkers ${ }^{3}$ showed that low $\mathrm{ScO}_{2}$ measured by NIRS in the first 48 hours after the Norwood operation has a strong association with adverse outcome. In their study, adverse outcome was defined as PCICU stay longer than 30 days, need for extracorporeal membrane oxygenation, or in-hospital death after 48 hours. Because none of our patients died after either the Norwood operation or the ASO, we defined adverse outcome as duration of PCICU treatment longer than the median in the respective patient group, which was 88 hours for the Norwood operation and 72 hours for the ASO. According to this definition, we could not detect any difference in $\mathrm{ScO}_{2}$ related to adverse outcome in either patients with HLHS or patients with TGA.

Hypocapnia has been shown to contribute to low postoperative $\mathrm{ScO}_{2}$ in patients with HLHS undergoing the Norwood operation. ${ }^{5}$ In our study we also demonstrated a relationship between $\mathrm{ScO}_{2}$ and $\mathrm{PCO}_{2}$ in patients with HLHS when calculating this relationship at the time of minimal $\mathrm{ScO}_{2}$. No similar association, however, could be found in neonates after the ASO. The fact that $\mathrm{PCO}_{2}$ relates to $\mathrm{ScO}_{2}$ in patients with HLHS might indicate simply that alterations in pulmonary blood flow through the MBTS and associated alterations in pulmonary blood flow contribute to some extent to cerebral desaturation after $\mathrm{CPB},{ }^{16}$ an effect that is not possible in patients with TGA because the pulmonary and systemic circulations are in series. Our data therefore suggest that early postoperative mechanical ventilation should aim to avoid any degree of hyperventilation in patients with a univentricular circulation and an aortopulmonary shunt. In our department, a postoperative arterial $\mathrm{PCO}_{2}$ of about $45 \mathrm{~mm} \mathrm{Hg}$ is the aim for this patient group. 


\section{Study Limitations}

Isoflurane decreases cerebral oxygen consumption and cerebrovascular resistance, with a resultant increase in $\mathrm{ScO}_{2} \cdot{ }^{17}$ The sudden cessation of isoflurane at the end the Norwood procedure may therefore also have contributed to postoperative cerebral desaturation. The design of this study does not allow us to distinguish between the effects of general anesthesia on $\mathrm{ScO}_{2}$ and those of CPB.

$\mathrm{SvO}_{2}$ was sampled from the central venous catheter placed in the superior vena cava. The $\mathrm{SvO}_{2}$ values reported here thus do not truly represent mixed venous oxygen saturation but rather venous blood flow from the brain, head, and upper extremities.

Cerebral NIRS values predominantly represent brain oxygenation but also that of adjacent and overlying tissues. A good and close correlation between cerebral NIRS values and sagittal sinus blood oxygenation has recently been demonstrated, however, in an animal study on newborn piglets. ${ }^{18}$

\section{CONCLUSIONS}

In conclusion, a depression of $\mathrm{ScO}_{2}$ as measured by NIRS is prevalent among neonates with complex congenital heart disease early after cessation of CPB. A dip in $\mathrm{ScO}_{2}$ was found both in patients with HLHS who had cyanosis after the Norwood operation and in patients with TGA who did not have cyanosis after the ASO. This result indicates that early postoperative cerebral desaturation is potentially induced by a direct effect of CPB on cerebral blood flow rather than by the presence of a univentricular circulation. Further prospective studies are warranted to develop treatment strategies to reduce the degree of cerebral desaturation.

Because routine measures of oxygen transport and delivery do not clearly indicate any cerebral desaturation, cerebral NIRS monitoring may be an important complementary tool in an attempt to comprehensively monitor neonates early after complex neonatal heart surgery. It seems essential in the development of postoperative treatment strategies that aim to prevent neurologic damage most likely resulting from cerebral desaturation.

We thank Anke Wegmann for her help in collecting the data. This article is part of the doctoral thesis of Elisabeth Nufer.

\section{References}

1. Furck AK, Uebing A, Hansen JH, Scheewe J, Jung O, Fischer G, et al. Outcome of the Norwood operation in patients with hypoplastic left heart syndrome: a 12-year single-center survey. J Thorac Cardiovasc Surg. 2010;139:359-65.

2. Prifti E, Crucean A, Bonacchi M, Bernabei M, Murzi B, Luisi SV, et al. Early and long term outcome of the arterial switch operation for transposition of the great arteries: predictors and functional evaluation. Eur J Cardiothorac Surg. 2002;22: 864-73.

3. Phelps HM, Mahle WT, Kim D, Simsic JM, Kirshbom PM, Kanter KR, et al. Postoperative cerebral oxygenation in hypoplastic left heart syndrome after the Norwood procedure. Ann Thorac Surg. 2009;87:1490-4.

4. Jöbsis FF. Noninvasive, infrared monitoring of cerebral and myocardial oxygen sufficiency and circulatory parameters. Science. 1977; 198:1264-7.

5. Hoffman GM, Stuth EA, Jaquiss RD, Vanderwal PL, Staudt SR, Troshynski TJ, et al. Changes in cerebral and somatic oxygenation during stage 1 palliation of hypoplastic left heart syndrome using continuous regional cerebral perfusion. J Thorac Cardiovasc Surg. 2004;127:223-33.

6. Prêtre R, Tamisier D, Bonhoeffer P, Mauriat P, Pouard P, Sidi D, et al. Results of the arterial switch operation in neonates with transposed great arteries. Lancet. 2001;357:1826-30.

7. Barnea O, Santamore WP, Rossi A, Salloum E, Chien S, Austin EH. Estimation of oxygen delivery in newborns with a univentricular circulation. Circulation. 1998;98:1407-13.

8. Kussman BD, Gauvreau K, DiNardo JA, Newburger JW, Mackie AS, Booth KL, et al. Cerebral perfusion and oxygenation after the Norwood procedure: comparison of right ventricle-pulmonary artery conduit with modified Blalock-Taussig shunt. J Thorac Cardiovasc Surg. 2007;133:648-55.

9. Kirshbom PM, Forbess JM, Kogon BE, Simsic JM, Kim DW, Raviele AA, et al. Cerebral near infrared spectroscopy is a reliable marker of systemic perfusion in awake single ventricle children. Pediatr Cardiol. 2007;28:42-5.

10. Li J, Van Arsdell GS, Zhang G, Cai S, Humpl T, Caldarone CA, et al. Assessment of the relationship between cerebral and splanchnic oxygen saturations measured by near-infrared spectroscopy and direct measurements of systemic haemodynamic variables and oxygen transport after the Norwood procedure. Heart. 2006;92:1678-85

11. Lucas SJ, Tzeng YC, Galvin SD, Thomas KN, Ogoh S, Ainslie PN. Influence of changes in blood pressure on cerebral perfusion and oxygenation. Hypertension. 2010;55:698-705.

12. Rasmussen P, Lundby C. Influence of changes in blood pressure on cerebral oxygenation: role of skin blood flow? Hypertension. 2010;56:e1.

13. Kurth CD, Levy WJ, McCann J. Near-infrared spectroscopy cerebral oxygen saturation thresholds for hypoxia-ischemia in piglets. J Cereb Blood Flow Metab. 2002;22:335-41.

14. Nollert G, Möhnle P, Tassani-Prell P, Uttner I, Borasio GD, Schmoeckel M, et al. Postoperative neuropsychological dysfunction and cerebral oxygenation during cardiac surgery. Thorac Cardiovasc Surg. 1995;43:260-4.

15. Sulek CA, Blas ML, Lobato EB. Milrinone increases middle cerebral artery blood flow velocity after cardiopulmonary bypass. J Cardiothorac Vasc Anesth. 2002;16:64-9.

16. Mora GA, Pizarro C, Jacobs ML, Norwood WI. Experimental model of single ventricle. Influence of carbon dioxide on pulmonary vascular dynamics. Circulation. 1994;90(5 Pt 2):II43-6.

17. Drummond JC, Todd MM, Scheller MS, Shapiro HM. A comparison of the direct cerebral vasodilating potencies of halothane and isoflurane in the New Zealand white rabbit. Anesthesiology. 1986;65:462-7.

18. Tichauer KM, Elliott JT, Hadway JA, Lee DS, Lee TY, St Lawrence K. Using near-infrared spectroscopy to measure the cerebral metabolic rate of oxygen under multiple levels of arterial oxygenation in piglets. J Appl Physiol. 2010; 109:878-85. 